\author{
Beata Bieszk-Stolorz ${ }^{*}$ \\ Uniwersytet Szczeciński
}

\title{
ANALIZA WPŁYWU DOŚWIADCZENIA ZAWODOWEGO NA INTENSYWNOŚĆ PODEJMOWANIA PRACY
}

\begin{abstract}
Streszczenie
Celem artykułu jest ocena wpływu stażu pracy na intensywność podejmowania zatrudnienia. Postawiono hipotezę, że zmienia się ono w zależności od doświadczenia zawodowego. Materiał badawczy stanowiły dane indywidualne 21398 osób zarejestrowanych w PUP w Szczecinie w 2012 r. obserwowanych do końca 2013 r. Wyodrębniono grupy bezrobotnych ze względu na staż pracy. Analizę przeprowadzono w trzech etapach. Pierwszy polegał na ocenie prawdopodobieństwa pozostania w bezrobociu w zależności od czasu jego trwania (estymator Flemingtona-Harringtona). W drugim etapie wyznaczono intensywność podejmowania zatrudnienia w zależności od czasu zarejestrowania w urzędzie pracy (model hazardu empirycznego). W trzecim etapie wykorzystano model hazardu średniego do porównania intensywności wychodzenia z bezrobocia w poszczególnych grupach.
\end{abstract}

Słowa kluczowe: hazard empiryczny, estymator Flemingtona-Harringtona, hazard średni, bezrobocie

* Adres e-mail: beatus@wneiz.pl. 


\section{Wprowadzenie}

W kontekście teorii poszukiwania na rynku pracy prawdopodobieństwo podjęcia zatrudnienia przez osobę bezrobotną jest iloczynem prawdopodobieństwa uzyskania oferty i prawdopodobieństwa przyjęcia tej oferty (Mortensen 1987). Pierwszy z tych czynników, czyli prawdopodobieństwo otrzymania oferty pracy, zależy m.in. od cech indywidualnych osoby bezrobotnej, takich jak: płeć, wiek, poziom wykształcenia, doświadczenie zawodowe, a także od stanu zapotrzebowania na rynku pracy, parametrów określających zasiłek dla bezrobotnych (czas trwania zasiłku, jego wysokość) i lokalnej specyfiki rynku pracy. Jeśli minimalny poziom płac, przy którym bezrobotny jest gotów podjąć zatrudnienie, spadnie wraz z upływem czasu trwania bezrobocia, to oferty pracy będą chętniej akceptowane przez osoby pozostające dłużej bez zatrudnienia. W tym przypadku mówi się o dodatniej zależności czasu trwania (Mortensen 1977). Jeżeli mamy pozytywną zależność czasu trwania, to prawdopodobieństwo podjęcia zatrudnienia $\mathrm{w}$ danym momencie rośnie wraz z czasem jego poszukiwania. W przypadku gdy osoba bezrobotna przez dłuższy okres traci motywację do poszukiwania pracy, to prawdopodobieństwo otrzymania oferty pracy może ulec zmniejszeniu. Mówi się wówczas o negatywnej zależności czasu trwania (Layard, Nickell, Jackman 1991). Ujemna zależność może wynikać z deprecjacji kapitału ludzkiego w czasie trwania bezrobocia (Phelps 1972). Innym jej powodem może być uznanie bezrobocia przez pracodawców za negatywny sygnał produktywności. Wynikiem tego jest niechęć do zatrudniania pracowników wcześniej bezrobotnych (Blanchard, Diamond 1994). Charakter zależności czasu trwania znajduje odzwierciedlenie w nachyleniu funkcji hazardu, czyli intensywności zajścia zdarzenia. Funkcja hazardu jest malejąca w przypadku negatywnej zależności czasu trwania, a rosnąca - pozytywnej zależności czasu trwania. W przypadku braku zależności funkcja hazardu jest stała ${ }^{1}$. W badaniach empirycznych pojawiają się funkcje intensywności wychodzenia z bezrobocia o różnych kształtach. Malejąca funkcja hazardu, czyli ujemna zależność czasu trwania, pojawiła się w niektórych badaniach bezrobocia w Wielkiej Brytanii (Lancaster 1979; Nickell 1979, Berg, Ours 1994). W innych badaniach zaobserwowano mniej lub bardziej poziome (równoległe do osi odciętych) funkcje hazardu. Oznacza to brak zależności intensywności od czasu trwania (Narendranathan, Nickell, Stern 1985; Narendranathan 1993).

1 Szerzej na ten temat w: McVicar, Podivinsky (2003). 
W analizach bezrobocia pojawiają się również niemonotoniczne funkcje hazardu. W tym przypadku często powtarza się kształt „odwróconej litery U” (Arulampalam, Stewart 1995; Boheim, Taylor 2000) oraz „kolce” (tymczasowe skoki w prawdopodobieństwie wyjścia z bezrobocia) (Meyer 1990; Carling, Edin, Harkman, Holmlund 1996).

Funkcję hazardu można wyznaczać dla szeroko pojętej zmiennej - czasu. Może to być czas trwania w bezrobociu, liczony od momentu przejścia w stan bezrobocia do momentu podjęcia zatrudnienia, lub czas trwania ostatniego zatrudnienia. Celem artykułu jest ocena wpływu stażu pracy na intensywność podejmowania zatrudnienia. Postawiono hipotezę, że zmienia się ona w zależności od doświadczenia zawodowego.

\section{Dane statystyczne wykorzystane w badaniu}

W badaniu wykorzystano anonimowe dane indywidualne 21398 osób bezrobotnych zarejestrowanych w Powiatowym Urzędzie Pracy w Szczecinie w 2012 r. Osoby te obserwowano przez 24 miesiące, czyli do końca 2013 r. Dane zawierały datę rejestracji i wyrejestrowania, co umożliwiło wyznaczenie indywidualnego czasu zarejestrowania w urzędzie. Wyrejestrowanie następowało z różnych przyczyn. Jeżeli obserwacja zakończyła się wyrejestrowaniem z powodu podjęcia szeroko rozumianego zatrudnienia: podjęcie pracy, prac interwencyjnych, prac społecznie użytecznych, podjęcie działalności gospodarczej, to uznano ją za obserwację pełną. Dane przyjęto za cenzurowane ${ }^{2}$, jeżeli wyrejestrowanie nie nastąpiło do końca 2013 r. lub wyrejestrowanie nastąpiło przed końcem 2013 r. z przyczyny innej niż podjęcie zatrudnienia. Wyodrębniono 8 grup osób bezrobotnych ze względu na staż pracy. Pierwsza $\mathrm{z}$ nich $\left(P_{1}\right)$ to osoby nie deklarujące żadnego doświadczenia zawodowego, a ostatnia grupa $\left(P_{8}\right)$ to osoby, które przepracowały powyżej 30 lat. $\mathrm{W}$ pozostałych przypadkach staż pracy podzielono na okresy pięcioletnie. Tabela 1 przedstawia liczebność poszczególnych grup osób bezrobotnych. Najliczniejsza jest grupa bezrobotnych, którzy przepracowali do 5 lat $(38,0 \%)$, a najmniej liczna jest grupa osób, które przepracowały od 15 do 20 lat (4,4\%). Podobnie było w 2012 r. dla

\footnotetext{
2 Szerzej na temat cenzurowania w: Frątczak, Gach-Ciepiela, Babiker (2005, s. 47-54).
} 
całej Polski - odpowiednio 38,3\% oraz 3,9\% ${ }^{3}$. Duży jest odsetek osób bez doświadczenia zawodowego $(17,9 \%)$.

Tabela 1. Liczebność grup obserwowanych osób bezrobotnych

\begin{tabular}{|c|c|c|c|c|c|}
\hline \multirow{2}{*}{\multicolumn{2}{|c|}{$\frac{\text { Cecha }}{\text { Razem }}$}} & \multirow{3}{*}{$\begin{array}{c}\text { Obserwacje pełne } \\
8559 \\
1009\end{array}$} & \multirow{3}{*}{$\begin{array}{c}\begin{array}{c}\text { Obserwacje } \\
\text { cenzurowane }\end{array} \\
12839 \\
2819\end{array}$} & \multicolumn{2}{|c|}{ Razem } \\
\hline & & & & 21398 & $100,0 \%$ \\
\hline \multirow{8}{*}{ 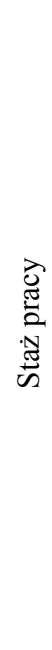 } & brak stażu $\left(P_{1}\right)$ & & & 3828 & $17,9 \%$ \\
\hline & $(0,5\rangle \quad\left(P_{2}\right)$ & 3143 & 4996 & 8139 & $38,0 \%$ \\
\hline & $(5,10\rangle \quad\left(P_{3}\right)$ & 1520 & 1614 & 3134 & $14,7 \%$ \\
\hline & $(10,15\rangle \quad\left(P_{4}\right)$ & 739 & 811 & 1550 & $7,2 \%$ \\
\hline & $(15,20\rangle \quad\left(P_{5}\right)$ & 457 & 488 & 945 & $4,4 \%$ \\
\hline & $(20,25\rangle \quad\left(P_{6}\right)$ & 810 & 909 & 1719 & $8,0 \%$ \\
\hline & $(25,30\rangle \quad\left(P_{7}\right)$ & 484 & 581 & 1065 & $5,0 \%$ \\
\hline & powyżej 30 lat $\left(P_{8}\right)$ & 397 & 621 & 1018 & $4,8 \%$ \\
\hline
\end{tabular}

Źródło: opracowanie własne.

Oczywiste jest to, że doświadczenie zawodowe ma związek z wiekiem. Osoby starsze mają większe szanse na długi staż pracy niż osoby młodsze. Zbadano strukturę osób bezrobotnych ze względu na staż pracy i wiek (rysunek 1). W przeprowadzonej analizie przyjęto podział na sześć grup wieku: 18-24 $\left(W_{1}\right), 25-34\left(W_{2}\right)$, 35-44 $\left(W_{3}\right), 45-54\left(W_{4}\right), 55-59\left(W_{5}\right), 60-64\left(W_{6}\right)$. Im dłuższy staż, tym mniej odpowiadających mu grup wieku. Wśród osób bez doświadczenia zawodowego są bezrobotni ze wszystkich grup wieku, a w grupie osób deklarujących ponad 30-letni staż pracy znajdują się osoby starsze (z grup wieku: $W_{4}, W_{5}, W_{6}$ ).

\footnotetext{
3 Opracowano na podstawie danych zawartych w: Bezrobocie rejestrowane... (2013).
} 
Rysunek 1. Struktura osób bezrobotnych ze względu na staż pracy i wiek

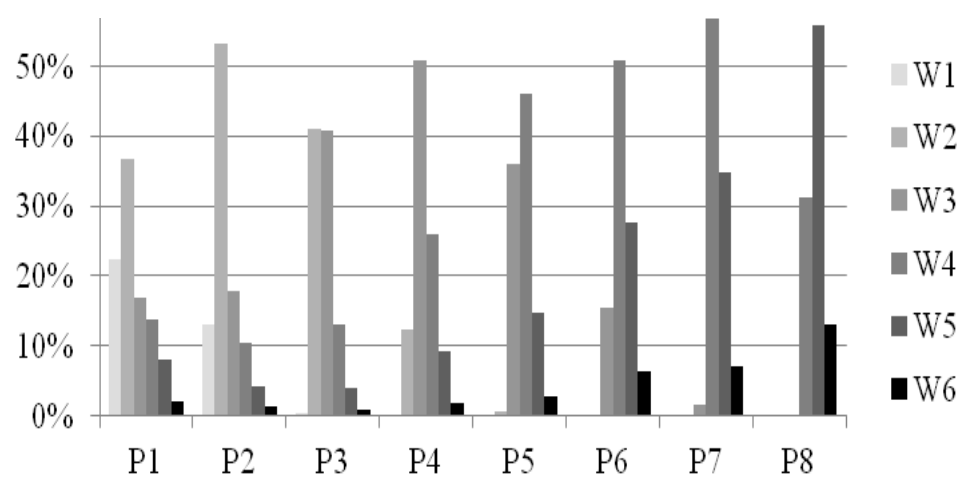

Źródło: opracowanie własne.

\section{Metodyka badania}

W analizie zastosowano metody zaliczane do analizy historii zdarzeń ${ }^{4}$. Zbadano średnią intensywność podejmowania zatrudnienia w zależności od stażu pracy osoby bezrobotnej. W tym celu wykorzystano wzór na średni hazard, wywodzący się z teorii niezawodności (bezawaryjności). Jego podstawą jest wyznaczenie średniej wartości funkcji określonej wzorem:

$$
\mu_{[a, b]}=\frac{\int_{a}^{b} f(x) d x}{b-a}
$$

gdzie $f$ jest funkcją całkowalną i ograniczoną w przedziale $\langle a, b\rangle$. Ponieważ analizowaną funkcją w tym przypadku jest funkcja hazardu $h \mathrm{w}$ przedziale $\langle 0, t\rangle$, to wzór (1) przyjmuje postać:

4 Szerzej o zastosowaniu metod analizy historii zdarzeń w badaniu bezrobocia w: Bieszk-Stolorz (2013). 


$$
\mu(t)=\frac{\int_{0}^{t} h(x) d x}{t}
$$

przy czym $y=h(t)$ jest funkcją hazardu (intensywności), a $H(t)=\int_{0}^{t} h(x) d x$ jest hazardem skumulowanym. Można zatem wzór na średnią intensywność zajścia zdarzenia $\bar{h}(t)$ w przedziale od 0 do $t$ dla czasu ciągłego zapisać jako:

$$
\bar{h}(t)=\frac{H(t)}{t}
$$

Dla czasu dyskretnego hazard skumulowany określony jest wzorem:

$$
H(t)=\sum_{j: t_{j} \leq t} h_{j}
$$

Do oceny intensywności podejmowania zatrudnienia w kolejnych miesiącach $j$ od momentu zarejestrowania wykorzystano estymator hazardu ${ }^{5}$ :

$$
\hat{h}_{j}=\frac{d_{j}}{n_{j}} \operatorname{dla} j=1,2, \ldots, k
$$

gdzie:

$d_{j}$ - liczba zdarzeń w j-ym miesiącu,

$n_{j}-$ liczba jednostek objętych obserwacją $j$-ym miesiącu.

W przeprowadzonym badaniu obserwacji dokonywano w kolejnych miesiącach w ciągu 2 lat, więc $k=24$. Wartość hazardu w danym momencie jest chwilowym potencjałem pojawiającego się zdarzenia. Wzór (4) przyjmuje zatem postać:

5 Na temat sposobów estymowania funkcji hazardu można przeczytać w: Balicki (2006, s. 85). 


$$
\hat{H}(t)=\sum_{j: t_{j} \leq t} \frac{d_{j}}{n_{j}}
$$

Jest to estymator skumulowanej funkcji hazardu Nelsona-Aalena. Korzystając z niego, można estymować funkcję trwania metodą nieparametryczną, czyli wyznaczyć estymator Flemingtona-Harringtona:

$$
\hat{S}(t)=\exp (-\hat{H}(t))
$$

Funkcja trwania w bezrobociu opisuje w tym przypadku prawdopodobieństwo niepodjęcia zatrudnienia przez osoby zarejestrowane w urzędzie pracy.

Ostatecznie wzór (3) przyjmuje postać:

$$
\bar{h}(t)=\frac{\sum_{j: t_{j} \leq t} \frac{d_{j}}{n_{j}}}{t}
$$

\section{Analiza wpływu stażu pracy na prawdopodobieństwo i intensyw- ność wychodzenia $z$ bezrobocia}

Badanie przeprowadzono $\mathrm{w}$ trzech etapach. W pierwszym etapie oszacowano estymator Flemingtona-Harringtona (7) w podgrupach bezrobotnych zarejestrowanych w urzędzie pracy, wyodrębnionych ze względu na staż pracy. Posłużył on do oceny prawdopodobieństwa pozostania $\mathrm{w}$ bezrobociu w zależności od czasu jego trwania. Zdecydowanie najwolniej z bezrobocia wychodziły osoby bez doświadczenia zawodowego $\left(P_{1}\right)$ i po 24 miesiącach obserwacji około $54 \%$ z nich pozostało w rejestrze urzędu pracy. W podobnej sytuacji, ale nieco lepszej, były osoby z ponad 30-letnim stażem pracy $\left(P_{8}\right)$. Po dwóch latach $42 \%$ z nich nadal oczekiwało na propozycję zatrudnienia. W najlepszej sytuacji na rynku pracy były osoby należące do grupy $P_{3}$, czyli takie, które przepracowały co najmniej 5 i co najwyżej 10 lat. Po 24 miesiącach w rejestrze urzędu pozostało około $33 \% \mathrm{z}$ nich. 
Rysunek 2. Prawdopodobieństwo niepodjęcia pracy według stażu pracy

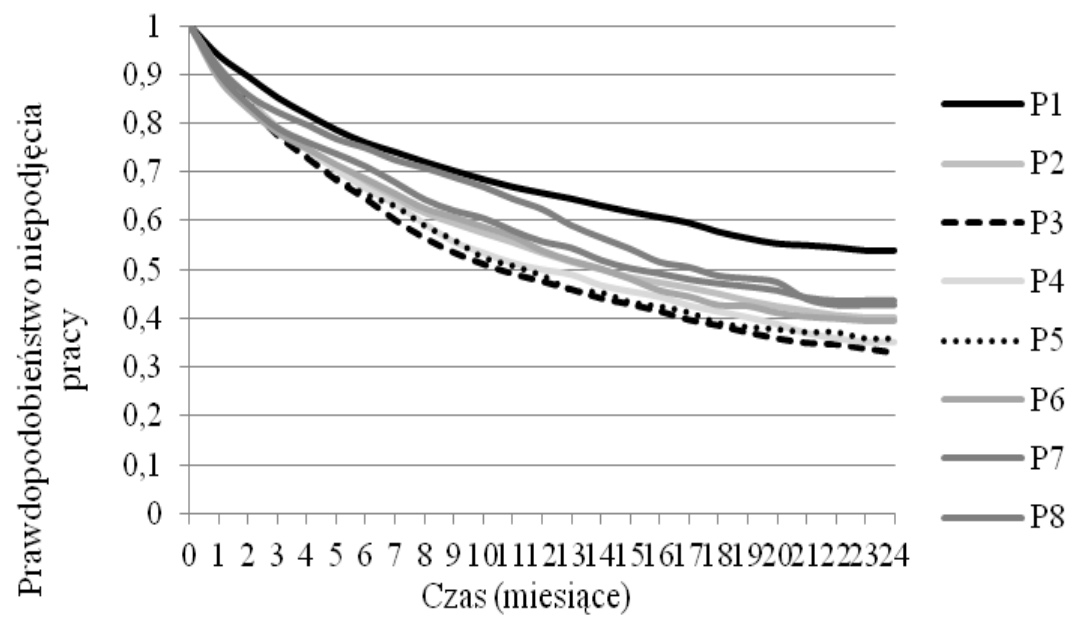

Źródło: opracowanie własne.

Tabela 2. Różnice w przebiegu krzywych trwania w bezrobociu według stażu pracy

\begin{tabular}{|c|c|c|c|c|c|c|c|c|}
\hline Grupa & $P_{1}$ & $P_{2}$ & $P_{3}$ & $P_{4}$ & $P_{5}$ & $P_{6}$ & $P_{7}$ & $P_{8}$ \\
\hline$P_{1}$ & $\mathrm{X}$ & 0,0000 & 0,0000 & 0,0000 & 0,0000 & 0,0000 & 0,0000 & 0,0105 \\
\hline$P_{2}$ & 0,0000 & $\mathrm{X}$ & 0,0013 & $\mathbf{0 , 3 1 0 8}$ & $\mathbf{0 , 0 9 6 3}$ & $\mathbf{0 , 4 2 8 1}$ & $\mathbf{0 , 3 5 5 1}$ & 0,0000 \\
\hline$P_{3}$ & 0,0000 & 0,0013 & $\mathrm{X}$ & $\mathbf{0 , 1 4 8 0}$ & $\mathbf{0 , 6 7 4 3}$ & 0,0433 & 0,0012 & 0,0000 \\
\hline$P_{4}$ & 0,0000 & $\mathbf{0 , 3 1 0 8}$ & $\mathbf{0 , 1 4 8 0}$ & $\mathrm{X}$ & $\mathbf{0 , 4 8 9 8}$ & $\mathbf{0 , 6 1 0 0}$ & $\mathbf{0 , 0 7 8 0}$ & 0,0000 \\
\hline$P_{5}$ & 0,0000 & $\mathbf{0 , 0 9 6 3}$ & $\mathbf{0 , 6 7 4 3}$ & $\mathbf{0 , 4 8 9 8}$ & $\mathrm{X}$ & $\mathbf{0 , 2 5 3 1}$ & 0,0300 & 0,0000 \\
\hline$P_{6}$ & 0,0000 & $\mathbf{0 , 4 2 8 1}$ & 0,0433 & $\mathbf{0 , 6 1 0 0}$ & $\mathbf{0 , 2 5 3 1}$ & $\mathrm{X}$ & $\mathbf{0 , 2 1 8 6}$ & 0,0002 \\
\hline$P_{7}$ & 0,0000 & $\mathbf{0 , 3 5 5 1}$ & 0,0012 & $\mathbf{0 , 0 7 8 0}$ & 0,0300 & $\mathbf{0 , 2 1 8 6}$ & $\mathrm{X}$ & 0,0171 \\
\hline$P_{8}$ & 0,0105 & 0,0000 & 0,0000 & 0,0000 & 0,0000 & 0,0002 & 0,0171 & $\mathrm{X}$ \\
\hline
\end{tabular}

Źródło: opracowanie własne.

Krzywe trwania przedstawione na rysunku 2 są do siebie zbliżone. W związku z tym za pomocą testu Gehana zbadano istotność różnic w przebiegu każdych dwóch wyznaczonych krzywych trwania w bezrobociu (tabela 2). Pogrubieniem zaznaczono przypadki, kiedy przeprowadzony test wskazuje na to, że na poziomie istotności $p=0,05$ nie ma podstaw do odrzucenia hipotezy mówiącej o równości krzywych 
trwania. Analizując wyniki zamieszczone w tabeli 2, można wysnuć wniosek, że osoby bez stażu pracy $\left(P_{1}\right)$ i pracujące powyżej 30 lat $\left(P_{8}\right)$ stanowiły odrębne grupy różniące się od pozostałych pod względem szybkości wychodzenia z bezrobocia. Prawdopodobieństwo podejmowania pracy po czasie $t$ od momentu zarejestrowania przez bezrobotnych należących do pozostałych grup stażu było zbliżone.

Drugi etap analizy polegał na porównaniu intensywności podejmowania zatrudnienia przez bezrobotnych w zależności od czasu trwania w bezrobociu w poszczególnych grupach wyodrębnionych ze względu na staż pracy (rysunek 3). W tym celu skorzystano z modelu hazardu empirycznego określonego wzorem (5). W pierwszych sześciu miesiącach od momentu zarejestrowania występuje negatywna zależność czasu trwania. Stopa hazardu dla wszystkich wyodrębnionych grup była malejąca, przy czym największą intensywnością i jednocześnie bardzo dużym jej spadkiem w pierwszych 4 miesiącach charakteryzowała się grupa $P_{6}$, czyli osoby ze stażem pracy od 20 do 25 lat. Najniższą intensywnością i najmniejszym jej spadkiem charakteryzowały się osoby bez doświadczenia zawodowego $\left(P_{1}\right)$. Bezrobotni powyżej 30 lat pracy w pierwszych dwóch miesiącach mieli stopę hazardu na średnim poziomie, ale po tym czasie nastąpił jej gwałtowny spadek. Po 6 miesiącach trwania bezrobocia można zaobserwować okresowe wzrosty i spadki stopy hazardu.

Rysunek 3. Intensywność podejmowania zatrudnienia przez osoby bezrobotne według stażu pracy

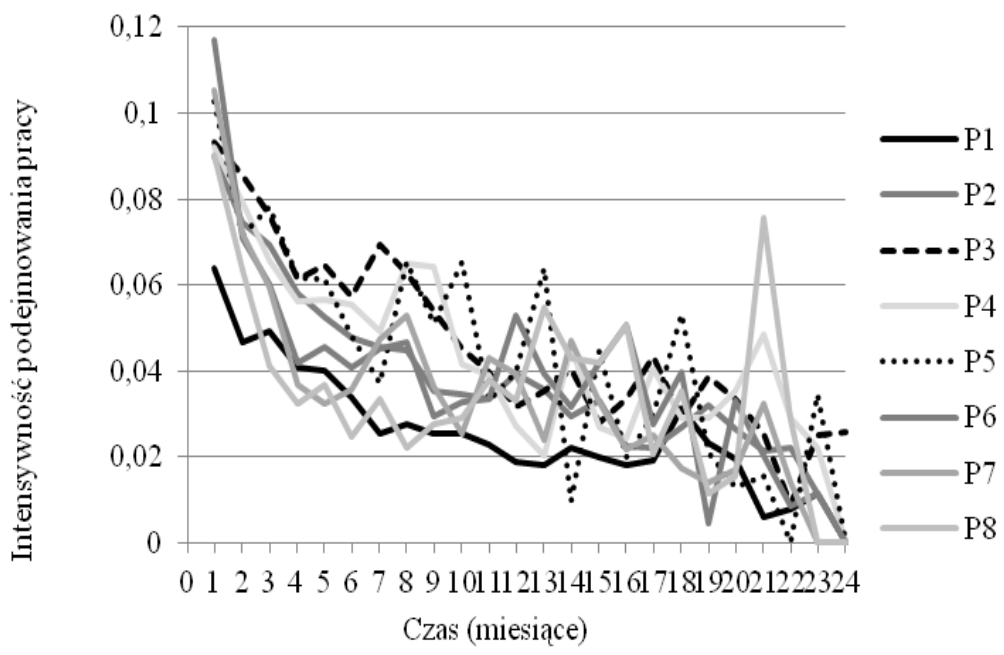

Źródło: opracowanie własne. 
W trzecim etapie analizy wyznaczono hazardy średnie, korzystając ze wzoru (8). Umożliwiły one porównanie średnich intensywności wychodzenia $\mathrm{z}$ bezrobocia w poszczególnych grupach bezrobotnych wyodrębnionych ze względu na staż pracy (rysunek 4).

Rysunek 4. Średnia intensywność podejmowania pracy przez osoby bezrobotne według grup stażu

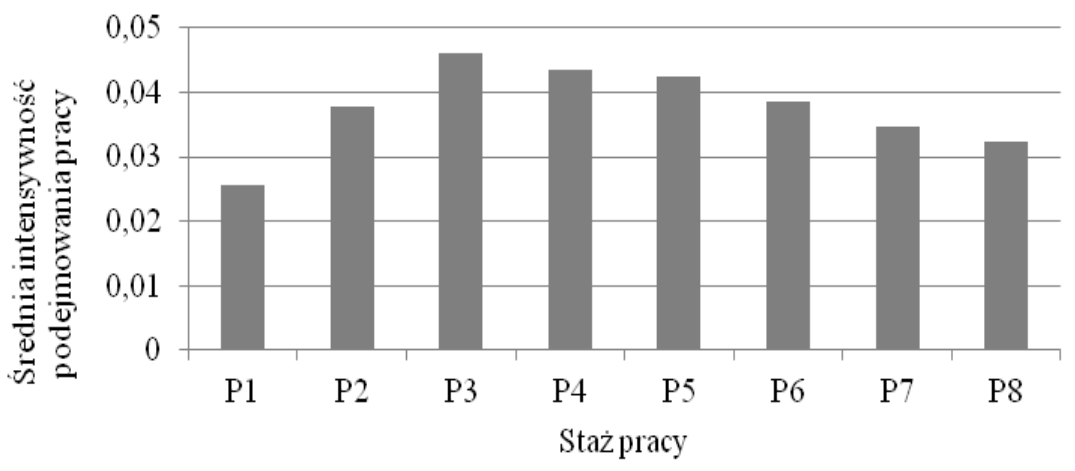

Źródło: opracowanie własne.

Średnie intensywności podejmowania pracy przez osoby bezrobotne według grup stażu pracy przyjmują kształt zbliżony do odwróconej litery U. Wynika z tego, że intensywność wychodzenia $\mathrm{z}$ bezrobocia była najniższa w przypadku osób bez doświadczenia zawodowego. Następnie wraz z wydłużaniem się stażu pracy rosła i przyjęła wartość największą dla bezrobotnych, którzy przepracowali od 10 do 15 lat $\left(P_{3}\right)$. Potem nastąpił stopniowy spadek intensywności.

\section{Podsumowanie}

Przeprowadzona analiza potwierdziła hipotezę, że intensywność wychodzenia $\mathrm{z}$ bezrobocia zmieniała się $\mathrm{w}$ zależności od doświadczenia zawodowego. Badania przeprowadzone na wszystkich trzech etapach pokazały, że grupy osób bezrobotnych o największym stażu pracy i bez jakiegokolwiek doświadczenia zawodowego różniły się istotnie od pozostałych grup. Powodem był wiek osób bezrobotnych, do którego należy odnieść ogólne wnioski wynikające z badania. Średnia intensyw- 
ność wychodzenia z bezrobocia była najmniejsza w przypadku osób bez stażu pracy, a także w przypadku osób z najdłuższym stażem. W pierwszej z wymienionych grup są osoby młode, które dopiero co ukończyły szkołę, czyli bez doświadczenia zawodowego spełniającego oczekiwania pracodawcy. Osoby ze stażem pracy powyżej trzydziestu lat to osoby starsze. W ich sytuacji pojawia się problem deprecjacji kapitału ludzkiego, szczególnie w przypadku osób starszych długotrwale bezrobotnych. Pracodawcy mogą postrzegać takie osoby jako mało elastyczne w zakresie przekwalifikowania się i zdobywania nowych umiejętności oraz mogą obawiać się o ich stan zdrowia. Należy jednak zauważyć, że osoby z dużym stażem pracy są i tak w lepszej sytuacji niż te bez jakiegokolwiek doświadczenia zawodowego, gdyż charakteryzują się wyższą średnią intensywnością wychodzenia z bezrobocia i mniejszym prawdopodobieństwem pozostania $\mathrm{w}$ rejestrze urzędu pracy. Na rynku pracy osoby starsze miały większe szanse na podjęcie zatrudnienia niż osoby bardzo młode, ale musiały mieć odpowiednio długi staż pracy. Bezrobotni z ponad 30-letnim doświadczeniem zawodowym mieli najwyższą intensywność podejmowania pracy w pierwszych miesiącach bezrobocia. Później spadała ona szybko, dorównując poziomem innym grupom. Zależność średniej intensywności podejmowania zatrudnienia od stażu pracy była podobna do zależności współczynnika aktywności zawodowej od wieku, która również ma kształt odwróconej litery $\mathrm{U}^{6}$. W najlepszej sytuacji na rynku pracy były osoby w średnim wieku, ze stażem pracy od 5 do 20 lat. Są to też osoby charakteryzujące się wysoką aktywnością zawodową. Z przeprowadzonej analizy wynika, że staż pracy determinuje intensywność podejmowania zatrudnienia, ale wyniki należy interpretować w odniesieniu do wieku osoby bezrobotnej.

\section{Literatura}

Arulampalam W., Stewart M. (1995), The determinants of individual unemployment durations in an era of high unemployment, „Economic Journal”, vol. 105.

Balicki A. (2006), Analiza przė̇ycia i tablice wymieralności, PWE, Warszawa.

Berg G. van den, Ours J.C. van (1994), Unemployment dynamics and duration dependence in France, the Netherlands and the United Kingdom, „Economic Journal”, vol. 104.

Bezrobocie rejestrowane I-IV kwartat 2012 r. (2013), GUS, Warszawa.

6 Szerzej na ten temat w: Węziak-Białowolska, Kotowska (2014, s. 81). 
Bieszk-Stolorz B. (2013), Analiza historii zdarzeń w badaniu bezrobocia, Volumina.pl Daniel Krzanowski, Szczecin.

Blanchard O., Diamond P. (1994), Ranking, unemployment duration and wages, ,Review of Economic Studies", vol. 61 (3).

Boheim R., Taylor M. (2000), Unemployment duration and exit states in Britain, University of Essex, Mimeo.

Carling K., Edin P.A., Harkman A., Holmlund B., 1996, Unemployment duration, unemployment benefits and labor market programs in Sweden, „Journal of Public Economics”, vol. 59 (3).

Frątczak E., Gach-Ciepiela U., Babiker H. (2005), Analiza historii zdarzeń. Elementy teorii, wybrane przykłady zastosowań, SGH, Warszawa.

Lancaster T. (1979), Econometric methods for the duration of unemployment, „Econometrica", vol. 47 (4).

Layard R., Nickell S., Jackman R. (1991), Unemployment, Macreconomic Performance and the Labour Market, Oxford University Press, Oxford.

McVicar D., Podivinsky J.M. (2003), Young People, Unemployment Duration and the New Deal in Northern Ireland, Evaluation Report no. 5, Department for Employment and Learning, Belfast.

Meyer B.D. (1990), Unemployment insurance and unemployment spells, „, Econometrica”, vol. 58.

Mortensen D. (1977), Unemployment insurance and job search decisions, „Industrial and Labor Relations Review”, vol. 30 (4).

Mortensen D. (1987), Job search and labour market analysis, w: Handbook of Labour Economics, t. 2, red. O. Ashenfelter, R. Layard, Amsterdam.

Narendranathan W. (1993), Job search in a dynamic environment: An empirical analysis, Oxford Economic Papers.

Narendranathan W., Nickell S., Stern J. (1985), Unemployment benefits revisited, „Economic Journal", vol. 95.

Nickell S. (1979), Estimating the probability of leaving unemployment, „Econometrica”, vol. 47.

Phelps E. (1972), Inflation Policy and Unemployment Theory: The Cost Benefit Approach to Monetary Planning, MacMillan, London.

Węziak-Białowolska D., Kotowska I.E. (2014), Pomiar kapitału ludzkiego i jego zróżnicowanie wedtug cech demograficznych, społecznych i ekonomicznych, w: Rynek pracy $i$ wykluczenie w kontekście percepcji Polaków. Diagnoza społeczna 2013. Raport tematyczny, red. I.E. Kotowska, Warszawa. 


\title{
THE ANALYSIS OF PROFESSIONAL EXPERIENCE IMPACT ON EMPLOYMENT INTENSITY
}

\begin{abstract}
The purpose of the article is to assess the impact of overall employment duration on the employment intensity. A hypothesis has been made that this intensity changes depending on one's professional experience. The research material included the individual data of 21398 individuals registered by the Poviat Labour Office in Szczecin in 2012 which were observed till the end of 2013. The registered unemployed were divided into groups according to the duration their professional experience. The analysis was conducted in three stages. First of all, the author assessed the odds of remaining in unemployment depending on its duration (the Flemington-Harrington estimator). Secondly, the intensity of employment in correlation with the time of staying on the PLO registration list (the empirical hazard model) was calculated. Finally, the average hazard model was used to compare the intensity of unemployment leaving in each group.
\end{abstract}

Translated by Anita Zdrojewska

Keywords: empirical hazard model, Flemington-Harrington estimator, average hazard rate, unemployment

JEL Codes: C51, J64 
